\title{
A ATUALIDADE DO PENSAMENTO DE CARRARA NO DIREITO PENAL
}

\author{
Ivette Senise Ferreira \\ Professora Associada da Faculdade de Direito da Universidade de São Paulo
}

\begin{abstract}
Resumo: Francesco CARRARA ocupa posição de destaque na ciência jurídico-penal contemporânea, pelo valor cultural de sua obra e pela influência que exerceu na legislação e na doutrina de inúmeros países. No Brasil, essa influência foi reconhecida pelo legislador no passado mas pode também ser afirmada no presente, demonstrando a atualidade de seu pensamento, que ainda é lembrado para fundamentar soluções ou auxiliar na interpretação dos textos legais. A autora enfatiza a influência de CARRARA na legislação e na doutrina penal, demonstrando a atualidade da obra do grande penalista, tema com o qual foi ele homenageado por ocasião do primeiro centenário de sua morte, num Congresso internacional realizado em Lucca, na Itália, em 1988.
\end{abstract}

Resumé: La valeur culturelle de l'oeuvre de Francesco CARRARA et la renomée qu'il a acquis lui ont assuré une place prépondérante dans la moderne science juridique pénale. Son influence a été reconnue dans les lois et dans la doctrine de plusieurs nations. Au Brésil elle a été referée par notre legislateur de 1940, mais existe encore dans la nouvelle loi de 1984 et dans l'oeuvre des auteurs contemporains, due à l'actualité de sa pensée.

Unitermos: A influência de Carrara na legislação penal brasileira; O pensamento de Carrara na moderna doutrina penal brasileira.

\section{INTRODUÇÃO}

O valor cultural da obra de Francesco Carrara e o renome que conquistou além das fronteiras de sua terra natal não somente tornaram-no merecedor das honras e homenagens que recebeu das sociedades científicas do mundo inteiro, mas também asseguraram a posição de destaque que até hoje ocupa, com seus ensinamentos, na ciência jurídico-penal contemporânea, embora tenham decorrido cem anos do seu desaparecimento, tendo lançado raízes que frutificaram na legislação e na doutrina de inúmeros países.

A sua influência no Brasil foi expressamente reconhecida pelo legislador no passado, e a atualidade do seu pensamento na nossa doutrina evidencia-se pela preocupação de nossos juristas em trazer o seu nome e os seus argumentos para fundamentar soluções ou interpretações que o Mestre já apontava com segurança e discernimento. 
A idéia de uma ordem de valores acima do homem e da sociedade, que esta deve procurar conservar, a idéia do delito como um ente jurídico e a da liberdade do homem, ao mesmo tempo súdito e conservador dos princípios morais, a da tutela jurídica como fundamento da repressão, são princípios básicos da doutrina estabelecida por Carrara que, com algumas modificações, não se acham ausentes do pensamento contemporâneo em matéria penal.

Chegaram ao seu apogeu na fase do Tecnicismo Jurídico, em que a autoridade de Rocco e a influência do Código penal italiano de 1930 se fizeram sentir no Brasil, moldando a nossa lei penal e fornecendo à doutrina os instrumentos para a sua interpretação.

A legislação brasileira atual, surgida em 1984 com a promulgação da Nova Parte Geral, que substituiu a primeira parte do Código penal de 1940, embora tenha trazido várias modificações substanciais nas normas relativas às espécies de penas e sua aplicação, e outros pontos relevantes da teoria do crime, conservou na Teoria Geral do Direito penal grande parte dos princípios existentes na legislação anterior, possibilitando que antigas e clássicas construções jurídicas equilibrassem as novidades procedentes da moderna doutrina e legislação alemã, de tal maneira que o nome de Carrara continua figurando nas citações dos juristas que atualmente promovem a adequação dos seus ensinamentos aos princípios contidos nas determinações das novas regras.

2. A influência de Carrara na legislação penal brasileira.

I - O código penal de 1940:

O Código penal anterior, de 1890, promulgado no Brasil após a proclamação da República, era de nítida inspiração positivista acompanhando as idéias predominantes na Europa que lhe eram contemporâneas. Mas, combatido desde o primeiro momento, por suas falhas, somente em 1940 foi promulgado outro Código, de tendências ecléticas, no qual o legislador procurou combinar os princípios da Escola Clássica com o que pôde aproveitar de melhor da Escola Positiva, principalmente as medidas de segurança para os casos de periculosidade do agente.

Na própria Exposição de Motivos que acompanhava o Projeto do Presidente da República, o Ministro da Justiça declarava:

"Coincidindo com a quase-totalidade das codificações modernas, projeto não reza em cartilhas ortodoxas, nem assume compromissos irretratáveis ou incondicionais com qualquer das escolas ou das correntes doutrinárias que se disputam o acerto na solução dos problemas penais. Ao invés de adotar uma política extremada em matéria penal, inclina-se para uma política de transação ou de conciliação. Nele, os postulados clássicos fazem causa comum com os princípios da Escola Positiva" 
Torna-se evidente, assim, a grande influência da doutrina esposada por Carrara na elaboração desse texto legislativo, e nela podemos destacar alguns pontos em que o relacionamento foi mais intenso:

\section{a) Princípio da legalidade.}

"Se l'uomo soggiace alla legge penale in quanto é ente dirigibile, questa sua subiezione ha causa nel suo intelletto e nella sua volontà. Ma a nessuno può attribuirsi la volontà di violare una legge o che non esiste o che ei non conosce. Dunque non può essere delitto un'azione se non è emanata $\mathrm{e}$ promulgata la legge che la proibisce" (CARRARA, Programma del Corso di diritto criminale, Lucca, 1877,5 - ed., vol. I, p. 47, § 19)

Nesse princípio básico da reserva legal, tão bem enunciado por Carrara, assenta-se o sistema punitivo brasileiro, vindo o mesmo inscrito no art. $1^{\circ}$ do nosso Código penal:

"Não há crime sem lei anterior que o defina. Não há pena sem prévia cominação legal"

\section{b) Autonomia da vontade.}

"Io non mi occupo di discussioni filosofiche: pressupongo accettata la dottrina del libero arbitrio e della imputabilità morale dell'uomo, e su questa base edificata la scienza criminale, che male si costruirebbe senza di quella". (CARRARA, op. cit., p. 38, no $^{2}$ )

O legislador brasileiro, recusando-se a entrar na controvérsia metafísica entre determinismo e livre-arbítrio, considerou expressamente porém a vontade humana como um postulado de ordem prática, reconhecendo que:

"Do ponto de vista ético-social, a autonomia da vontade humana é um a priori em relação à experiência moral, como o princípio da causalidade em relação à experiência física. Sem o postulado da responsabilidade moral, o direito penal deixaria de ser uma disciplina de caráter ético para tornar-se mero instrumento de utilitarismo social ou de prepotência do Estado. Rejeitado o pressuposto da vontade livre, o Código Penal seria uma congérie de ilogismos" (Exposição de Motivos do Código Penal de $\left.1940, n^{-} 4\right)$

\section{c) Responsabilidade moral.}

"La legge dirige l'uomo in quanto è un essere moralmente libero: onde a nessuno può chiedersi conto di un evento del quale sia stato causa puramente fisica, senza esserne menomamente causa morale". (CARRARA, op. cit., p. $43, \S 12$ ) 
A responsabilidade moral, implícita nas normas adotadas pelo legislador de 1940, foi expressamente reconhecida por este como fundamento da responsabilidade penal:

"A responsabilidade penal continua a ter como fundamento a responsabilidade moral, que pressupõe no autor do crime, contemporaneamente à ação ou omissão, a capacidade de entendimento e a liberdade de vontade, embora nem sempre a responsabilidade penal fique adstrita à condição de plenitude do estado de imputabilidade psíquica e até mesmo prescinda de sua coexistência com a ação ou omissão, desde que esta possa ser considerada libera in causa ou ad libertatem relata". (Exposição de Motivos do Código Penal de 1940, no 4)

\section{d) Imputabilidade.}

“Se l'intelletto, o la volontà, od ambedue, mancarono del tutto all'agente, non vi è intenzione, e non vi è per conseguenza imputabilità. Se o l'uno o l'altra, od ambedue furono soltanto minorati, vi resta una intenzione, ma imperfetta, vi resta imputabilità, ma minorata". (CARRARA, op. cit., p. $75, \S 65)$

Considerando também o elemento vontade como condição necessária para a responsabilidade penal, o legislador brasileiro distinguiu, para os efeitos desta, entre indivíduos imputáveis, inimputáveis e semi-imputáveis, baseando-se na sua capacidade de culpa moral. Assim, o art. 22 do Código penal determinou:

É isento de pena o agente que, por doença mental ou desenvolvimento mental incompleto ou retardado, era, ao tempo da ação ou da omissão, inteiramente incapaz de entender o caráter criminoso do fato ou de determinar-se de acordo com esse entendimento"

Parágrafo único: "A pena pode ser reduzida de um a dois terços, se o agente, em virtude de perturbação da saúde mental ou por desenvolvimento mental incompleto ou retardado, não possuía, ao tempo da ação ou da omissão, a plena capacidade de entender o caráter criminoso do fato ou de determinar-se de acordo com esse entendimento"

Esse dispositivo é quase a tradução literal de norma existente no Código penal suíço e constitui orientação que não está isolada nos estatutos modernos, embora alguns tenham preferido atribuir a essa segunda categoria de indivíduos a imposição de medidas de segurança.

\section{e) Culpabilidade.}

“La libertà è un attributo indispensabile della volontà: cossichè questa 
non può esistere senza di quella, nel modo stesso che non può essere materia senza gravità. (CARRARA, op. cit., p. 74, § 62)

"Dal concorso dell'intelletto e della volontà sorge la intenzione. La quale si definisce in genere - ' uno sforzo della volontà verso un certo fine - $e$ in specie - uno sforzo della volontà verso il delitto". (CARRARA, op. cit., p. 74, § 63)

"Il dolo si definisce - la intenzione più o meno perfetta di fare un atto che si conosce contrario alla legge”. (CARRARA, op. cit., p. 77, § 69)

"La colpa si definisce - la volontaria omissione di diligenza nel calcolare le conseguenze possibili e prevedibili del proprio fatto". (CARRARA, op. cit., p. 88, § 80)

A teoria da vontade esposada por CARRARA foi seguida pelo legislador brasileiro de 1940, que acolheu a concepção de dolo e de culpa como elementos da culpabilidade, pressupondo no agente condições psíquicas que lhe permitam avaliar o ato a ser praticado em qualquer das duas modalidades, embora se abstenha de uma conceituação teórica da culpa stricto sensu. $O$ art. 15 do Código penal de 1940 preceituava:

"Diz-se o crime:

I - doloso, quando o agente quis o resultado ou assumiu o risco de produzí-lo;

II - culposo, quando o agente deu causa ao resultado por imprudência, negligência ou imperícia.

Parágrafo único: Salvo os casos expressos em lei, ninguém pode ser punido por fato previsto como crime, senāo quando o pratica dolosamente"

\section{f) Causas excludentes.}

"La forza morale del delitto cercata nella propria causa (ossia la sua forza morale soggettiva) è ciò che costituisce la moralità dell'azione. Q uesta non si ottiene se non per concorso di quattro requisiti che abbiano accompagnato la operazione interna, al seguito della quale l'uomo procedette alla operazione esterna. Tali condizioni sono - 1‥ cognizione della legge. $-2^{\circ}$. previsione degli effetti. $-1 !$, , libertà di eleggere. $-4 \stackrel{\circ}{\circ}$. volontà di agire" (CARRARA, op. cit., p. $73 \S 59$ )

"I primi due requisiti per la legge umana basta talvolta che esistano potenzialmente; gli ultimi due devono sempre esistere anche attualmente" (CARRARA, op. cit., p. $73 \S 60$ ) 
A combinação do concurso do intelecto, representado pelos dois primeiros requisitos, e do concurso da vontade, representado pelos dois últimos, tão bem exposta por Carrara, vai fundamentar também na legislação brasileira a possibilidade de afastar-se a punibilidade do agente nas situações em que esses requisitos faltem ou estejem perturbados por ato de terceiro. Assim acontece na coação irresistível e na obediência a ordem de superior hierárquico, segundo o art. 18 do Código penal de 1940:

"Se o crime é cometido sob coação irresistível ou em estrita obediência a ordem não manifestamente ilegal, de superior hierárquico, só é punível o autor da coação ou da ordem".

Nessa matéria referente à liberdade de escolha na determinação das ações do indivíduo, e na da influência das causas internas ou externas que podem alterar o seu ânimo e retirar-lhe a espontaneidade, os ensinamentos de Carrara encontraram eco em vários pontos relevantes:

"La forza che costringe l'uomo ad agire può essere fisica o morale. Fisica quando agisce sul corpo; morale quando agisce sull'animo". (CARRARA, op. cit., p. 218, § 278)

"Nel primo caso l'uomo dicesi invito; nel secondo coatto. L'invito non può essere mai responsabile in faccia alla legge penale. Esso non è ag ente, ma agito; la causa della infrazione non è egli, ma quella forza che si vale del suo corpo come stromento di un'azione, nella quale egli è meramente passivo" (CARRARA, op. cit., p. 218, § 279)

"Questo effetto della coazione morale o psicologica, che rendendo meno

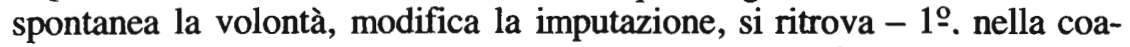
zione propriamente detta, o violenza morale esterna, $2^{\circ}$. nell'impeto degli affetti, 3‥ nella ubriachezza". (CARRARA, op. cit., p. 220, § 283)

Sensível aos argumentos expostos longamente por Carrara, o legislador brasileiro levou em conta a influência desses fatores na determinação do comportamento do indivíduo, através da composição do intelecto e da vontade, estabelecendo:

a) a exclusão da criminalidade do fato praticado em legítima defesa para repelir injusta agressão, atual ou iminente, a direito seu ou de outrem, com meios moderados e necessários (art. 19, n. II);

b) a exclusão da criminalidade do fato praticado em estado de necessidade, face à existência de um perigo atual, que não provocou por sua vontade nem podia de outro modo evitar (art. 19, n. I); 
c) a mera atenuação da pena nas alterações causadas pelos estados emotivos e passionais que, segundo a regra do art. 24 , não excluem a responsabilidade penal;

d) a variação da responsabilidade penal nas diferentes hipóteses de embriaguez:

1. se voluntária ou culposa, não pode determinar a exclusão da responsabilidade (art. 24, n. II);

2. se for acidental e completa, determina a isenção de pena (art. $24, \S^{19}$ );

3. se for acidental mas não completa, há uma atenuação da pena (art. 24 , $\S 29$;

4. se for pré-ordenada para cometer um crime, ocasiona a agravação da pena deste (art. 44, n. II, c).

\section{g) Erro de direito e erro de fato.}

A potência intelectiva e a liberdade de escolha podem também sofrer a influência de certas causas morais representadas pela ignorância (ausência de qualquer noção sobre o objeto jurídico) e o erro (falsa noção sobre o objetó).

"L'errore cade sui repporti dei proprii atti con la legge, tanto se conoscendo la legge si erra sulle condizioni che accompagnano il fatto, quanto se, ben conoscendo le condizioni del fatto, si erra circa la esistenza della legge proibitiva del fatto stesso. Cosi l'errore guardato in ordine all'oggetto su cui cade, può essere o di fatto o di diritto". (CARRARA, op. cit., p. 207, § 254)

"L'errore di diritto non scusa mai. Eșige politica che si presuma nel cittadini la cognizione della legge penale, che d'altronde è debito di ognuno di conoscere". (CARRARA, op. cit., p. 208, § 258)

O Código penal brasileiro de 1940 dispunha no seu art. 16 sobre a irrelevância do erro de direito, preferindo os argumentos de Carrara aos dos que pressionavam em prol da restrição a esse princípio:

“A ignorância ou a errada compreensão da lei não eximem de pena"

Concedia-se porém ao erro de direito escusável eficácia atenuante, no art. 48 , III. 
Na Exposição de Motivos do Código penal (no 14), o legislador justificou-se:

"O error juris nocet é, antes de tudo, uma exigência de política criminal. Se fosse permitido invocar como escusa a ignorância da lei, estaria seriamente embaraçada a ação social contra o crime, pois ter-se-ia criado para os malfeitores um pretexto elástico e dificilmente contestável. Impraticável seria, em grande número de casos, a prova contrária à exceção do réu, fundada na insciência da lei".

Sobre o erro de fato, dizia CARRARA:

"L'errore di fatto esime da ogni imputazione quando fu essenziale, e invincibile. In nulla peccò chi non credea di peccare, quando non gli era possibile di illuminarsi sulla pravità del suo fatto". (CARRARA, op. cit., p. $210, \S 260$ )

"L'errore di fatto essenziale quando è vincibile esime dalla imputazione in ragione di dolo, ma vi sostituice la responsabilità in ragione di colpa. Fu una omissione volontaria di diligenza il non riflettere a ciò che avrebbe dileguato l'errore. Questa voluntaria omissione fu causa della infrazione della legge. Dunque rimane una responsabilità". (CARRARA, op. cit., p. 211, § 263)

"L'errore di fatto, anche invincibile, non scusa se è accidentale, o concomitante. La volontà fu diretta al delitto; le varietà degli effetti, quando non modificano il delitto, non sono valutabili" (CARRARA, op. cit., p. $210, \S 261)$

O erro de fato foi objeto do art. 17, do Código de 1940, e seus parágrafos, que distinguiu, como ensinava Carrara, entre erro essencial e erro acidental para diferentes efeitos penais, conforme seja escusável ou invencível. Considerou erro relevante (erro de fato essencial) aquele que versa sobre fato constitutivo do crime ou o erro putativo:

"É isento de pena quem comete o crime por erro quanto ao fato que o constitui, ou quem, por erro plenamente justificado pelas circunstâncias, supõe situação de fato que, se existisse, tornaria a ação legítima (art. 17).

O erro culposo, considerado vencível, não elide a culpa estrita:

"Não há isenção de pena quando o erro deriva de culpa e o fato é punível como crime culposo" (art. 17, § 19).

"Responde pelo crime o terceiro que determina o erro" (art. 17, § 2 9). 
O erro acidental, considerado irrelevante, é disciplinado em duas modalidades:

a) error in objecto, error in persona:

“ $O$ erro quanto à pessoa contra a qual o crime é praticado não isenta de pena. Não se consideram, neste caso, as condiçōes ou qualidades da vítima, senão as da pessoa contra quem o agente queria praticar o crime" (art. 17, § 39).

b) aberratio ictus:

"Quando, por acidente ou erro no uso dos meios de execução, o agente, ao invés de atingir a pessoa que pretendia ofender, atinge pessoa diversa, responde como se tivesse praticado o crime contra aquela" (art. 53).

\section{h) Tentativa.}

A conceituação do crime tentado, no Código penal de 1940, com seus requisitos objetivos e subjetivos, acompanha o pensamento do grande Mestre italiano.

Na controvertida hipótese da tentativa inadequada, ou crime impossível, em que se discute sobre a conveniência de sua punibilidade, entendia Carrara que só a tentativa absolutamente impossível deveria ficar isenta de punição, pela ausência de perigo para o bem jurídico protegido. Somente o perigo resultante in concreto da atividade do agente (pericolo corso) é que justificaria a imposição de pena ao seu autor.

O Código penal brasileiro também considerou impunível a tentativa absolutamente impossível, no seu art. 14:

"Não se pune a tentativa quando, por ineficácia absoluta do meio ou por absoluta impropriedade do objeto, é impossível consumar-se o crime"

Mas, realizando uma transação com a doutrina contrária, determina, no seu art. 76, parágrafo único, e 94, n. III, a aplicação de medida de segurança (liberdade vigiada) quando essa tentativa impossível revelar periculosidade do agente, segundo avaliação que deve ser feita pelo Juiz.

\section{II - A Nova Parte Geral do Código Penal (Lei no 7.209, de 11/7/1984.}

O Código penal brasileiro de 1940 havia conseguido conciliar perspectivas doutrinárias diversas, por um lado adotando os princípios da Escola Clássi- 
ca, ao acolher o retributivismo fundado na responsabilidade moral, mas, por outro lado, havia contemporizado com os adeptos da Escola Positiva ao admitir a aplicação de medida de segurança ao agente considerado perigoso, fosse imputável ou inimputável.

Os movimentos de reforma dessa lei penal haviam culminado com a promulgação de um novo Código penal, em 1969, totalmente inadequado, pelo que esse Código nunca chegou a entrar em vigor. Nele procurava-se realizar uma simbiose da culpabilidade com a periculosidade para a individualização da pena e determinação de sua execução, consagrando-se a finalidade reeducativa das sanções penais, que deviam ser aplicadas no sentido de obter-se a recuperação moral do condenado e promover-se a defesa da sociedade.

A periculosidade passara para o centro do sistema penal, embora a culpabilidade devesse dar a medida da justa reprovação. Em decorrência das idéias da Nova Defesa Social, as finalidades da pena deviam amoldar-se ao objetivo de tratamento individualizado, conforme a personalidae do condenado.

A reintegração social do condenado, porém, nunca foi conseguida e os elevados índices de reincidência revelaram o fracasso dessa fase do Direito penal, que não deixara de apoiar-se nas penas de prisão, com todas as suas nefastas conseqüências.

A necessidade de adequar as normas penais às exigências da sociedade brasileira conduziu à reforma da legislação penal em 1984, quando uma Nova Parte Geral substituiu a primeira parte do Código penal de 1940, através da Lei 7.209, reservando-se a reformulação da Parte Especial, ainda em vigor, para uma fase posterior.

Apesar da adoção de uma nova filosofia pela nova lei, grande parte do ordenamento anterior foi mantido, modificando-se apenas alguns pontos considerados cruciais para a atualização da doutrina, implantando-se um novo sistema de penas, com destaque para as sanções alternativas da prisão.

A premissa dogmática, porém, é a do direito penal da culpa, fundado na relativa liberdade do homem e na sua conseqüente responsabilidade moral. Como observa Ricardo Antunes ANDREUCCI:

"Ressurge, portanto, o carrariano esquema clássico, voltado para a tutela das liberdades individuais".

(ANDREUCCI, R. - "culpabilidade e erro", in Reforma Penal, Saraiva, S. Paulo, 1985, p. 118)

O princípio da culpabilidade estende-se a todas às questões tratadas, diversificando a punição dos partícipes no concurso de pessoas, eliminando os 
resíduos da responsabilidade objetiva, abolindo a medida de segurança para os imputáveis:

Art. 29 - "Quem, de qualquer modo concorre para o crime incide nas penas a este cominadas, na medida de sua culpabilidade"

Art. 19 - "Pelo resultado que agrava especialmente a pena, só responde o agente que o houver causado ao menos culposamente".

A clássica divisão entre erro de direito e erro de fato foi substituída pelas formas básicas de erro construídas pela doutrina alemã: erro sobre elementos do tipo (Tatbestandsirrtum) e erro sobre a ilicitude do fato, ou erro de proibição (Verbotsirrtum), fundamentando-se todavia o tratamento penal exclusivamente no princípio nullum crimen sine culpa.

Permanecem contudo inalteradas as mesmas regras do : ódigo penal de 1940, já mencionadas neste trabalho, relativas ao conceito de tentativa (art. 14, II) e de crime impossível (art. 17), ao dolo e à culpa (art. 18), à inimputabilidade e semi-imputabilidade (art. 26), aos estados emotivos ou de embriaguez (art. 28), à coação irresistível e à obediência hierárquica (art. 22), ao erro putativo e ao erro sobre a pessoa (art. $20, \S 1^{\circ}$ e $\$ 3^{\circ}$ ), entre outras.

Em conseqüência, podem ser consideradas válidas e pertinentes todas as observações que nessas questões já foram apresentadas para ressaltar a influência de !'ARRARA na legislação brasileira anterior, que agora se renova.

Deve-se ainda frisar que a nova lei penal, embora tenha-se esforçado para humanizar o direito penal e o tratamento dos condenados, retomou a idéia de castigo como fundamento da pena, já que o delito constitui o menosprezo a um valor, cuja defesa cabe ao Estado promover. Assim ensina Miguel REALE JR.:

"É conseqüência da própria estrutura lógica da lei penal, fundada na eleição de valores, a natureza retributiva da sanção penal".

(REALE JR., M. - "Fundamento e aplicação das sanções penais na Nova Parte Geral", in Reforma Penal, Saraiva, S. Paulo, 1985, p. 64).

Como se percebe, não estamos longe da orientação dos clássicos e do pensamento de CARRARA...

\section{O pensamento de Carrara na moderna doutrina penal brasileira.}

A obra monumental de Carrara sempre foi conhecida dos juristas brasileiros, ávidos em atualizar seus conhecimentos com o pensamento dos grandes mestres europeus, mesmo porque foi no direito penal italiano que os reformistas 
da primeira metade deste século foram buscar a inspiração para o aperfeiçoamento de nossas normas penais. De que é prova o texto do Código penal de 1940, bem como o dos projetos que o antecederam, com a reprodução dos princípios e do sistema do Código penal italiano de 1930, em sua maior parte.

Conforme já se demonstrou, nessa lei foram aproveitados muitos ensinamentos do grande Mestre, com ampla repercussão de sua doutrina, que aqui circulava na versão espanhola ou no original. Em 1956, a lacuna editorial veio a ser preenchida com a edição em língua portuguesa da Parte Geral do "Programma del Corso di diritto criminale", em dois volumes, na bem-cuidada tradução dos magistrados J.L. AZEVEDO FRANCESCHINI e J.R. PRESTES BARRA. O pensamento do Mestre italiano tornava-se assim acessível a todos os estudiosos no Brasil, mas já vinha constituindo referência obrigatória na obra dos principais penalistas brasileiros, sobretudo os intérpretes da legislação brasileira como GALDINO SIQUEIRA ("Tratado de direito penal", J. Konfino Editor, R.J., 1947), A.J. da COSTA E SILVA ("Código penal anotado", Cia. Editora Nacional, S.P., 1943) e Nelson HUNGRIA ("Comentários ao Código Penal brasileiro", Ed. Forense, R.J., 1948).

Sua doutrina influenciou grandemente a obra dos representantes do tecnicismo jurídico no Brasil, entre os quais avulta o nome do grande mestre da Faculdade de Direito da Universidade de São Paulo, BASILEU GARCIA ("Instituiçōes de Direito Penal", Max Limonad, S. Paulo), que não poupou elogios a CARRARA, endossando vários de seus ensinamentos, como os referentes à culpabilidade e ao erro em matéria penal.

O brilho de suas teses alcançou autores mais recentes, como se verifica na obra de J. SALGADO MARTINS ("Direito penal", Saraiva, S.P., 1974), que ensina, citando o mestre: "O Direito, nos seus fundamentos, é uma disciplina moral". Referências à doutrina de Carrara enriquecem também as obras de Aníbal BRUNO ("Direito Penal", Forense, R.J., 1984), E. Magalhães NORONHA ("Direito Penal", Saraiva, S.P., 1985) e Damásio de JESUS ("Direito Penal", Saraiva, S.P., 1985).

Mas é nos "Comentários ao Código Penal", de Paulo José da : 'OSTA JR. (Saraiva, S.P., 1986), que o pensamento de CARRARA é revivido com toda a sua pujança, em vários conceitos que o autor não se furtou de valorizar ou endossar, como por exemplo na conceituação de agente provocador (p. 229), nas apreciações sobre o significado da reincidência (p. 328), sobre as circunstâncias do delito (p. 234), ou sobre o dano (p. 69), a imputabilidade (p. 210) ou ilicitude (p. 194).

\section{Conclusōes}

Adotando muitos dos princípios da Escola Clássica, embora fazendo concessōes a certas idéias positivistas o Código penal brasileiro de 1940, do qual 
ainda hoje vigora a Parte especial, tornou obrigatória através de suas normas a doutrina de CARRARA em muitos pontos relevantes.

As liçōes do grande Mestre não podiam assim deixar de refletir-se no pensamento jurídico nacional, e a força de suas idéias ilumina até hoje a obra de vários penalistas brasileiros, mesmo dos que não adotaram integralmente os seus ensinamentos.

Muitos dos conceitos que emitiu permanecem inalterados, tendo sido repetidos pelo legislador na reforma penal levada a termo recentemente, o que vem demonstrar o vigor e a atualidade das idéias de CARRARA, que merecidamente o situam entre os primeiros e o consagram como um dos maiores penalistas de nossa época. Lucca, Pisa, 25 de junho de 988 